\title{
A Ação dos EUA na Venezuela: ONGs, Sociedade Civil e Neoliberalismo
}

Recebido: 07-05-2019

Aprovado: 03-07-2019

Tiago Santos Salgado ${ }^{1}$

O presente artigo tem o objetivo de analisar a ação do corpo diplomático dos EUA na Venezuela durante o governo Chávez, em particular entre os anos de 2004 e 2009, a partir da análise de documentos disponibilizados no site Wikileaks. Tal documentação, que conta com documentos produzidos pelo Congresso dos EUA e telegramas enviados da embaixada estadunidense em Caracas demonstram a relação da diplomacia estadunidense na Venezuela e as suas relações com a oposição ao governo venezuelano, assim como as suas interpretações acerca da processualidade histórica em curso durante o período proposto.

Desde que Chávez chegou à presidência da Venezuela em 1999, o país latinoamericano se tornou um dos palcos mais importantes das lutas sociais na América Latina, uma vez que o então presidente representava uma ruptura com o sistema político até então existente, responsável pela implementação de políticas neoliberais que causaram uma série de tensões sociais e políticas no país. Ao dar início a intitulada Revolução Bolivariana, a antiga elite política venezuelana, que pela primeira vez desde 1958 se encontrava na oposição política, tendo sido derrotada nas urnas e perdendo o controle do Estado, começa a se articular para derrubar e desestabilizar o governo venezuelano, contando com apoio do governo dos EUA, que organizaram um golpe militar contra Chávez em 2002.

A Venezuela é entendida pelos EUA como um país de suma importância para sua política externa, uma vez que que conta com as maiores reservas de petróleo do mundo ${ }^{2}$ e geograficamente é próxima ao território estadunidense, o que facilita o comércio e diminui o

\footnotetext{
${ }^{1}$ Doutor em História pela PUC-SP. Membro do Centro de Estudos de História da América Latina (CEHALPUC-SP)

${ }^{2}$ Informação disponível em: http://comunicacao.fflch.usp.br/node/1618
} 
custo relativo do óleo. O petróleo venezuelano serviu de base para a industrialização e para lucros de empresas estadunidenses desde, ao menos, a década de 1920, quando o governo venezuelano possibilitou a chegada de empresas estrangeiras com a intenção de explorar o petróleo no país. Assim, existe um grande interesse por parte do governo dos EUA em manter seus privilégios em relação ao país latino-americano, entendido como fonte segura de matéria prima e mercado consumidor.

Durante boa parte do século passado, as relações entre os países foram de aproximação, tanto comercial como diplomática, sendo a Venezuela considerada um modelo de democracia para a América Latina, uma vez que a última ditadura militar no país terminou em 1958, quando se instaurou a democracia liberal no país, que aproveitando das grandes receitas petrolíferas, conseguiu organizar um sistema de conciliação de classes, em que os movimentos sociais, em especial os de esquerda, foram reprimidos, cumprindo a agenda da Guerra Fria, e a burguesia nacional e internacional conseguia exercer o poder político, utilizando as receitas do Estado para possibilitar grandes obras de infraestrutura e distribuir, mesmo que de forma mínima, as rendas provenientes do petróleo (CORONIL, 2017).

Para se entender a correlação de forças sociais, assim como a posição da Venezuela na estrutura de circulação do capital é importante analisar a riqueza natural existente no país, o petróleo, e demonstrar como tal riqueza natural é controlada pelo Estado. Assim, a disputa classista pelo controle do Estado no país representa não apenas o controle político, mas também a possibilidade de administrar uma das maiores riquezas naturais do planeta, indispensável para a circulação e para a acumulação capitalista. Portanto, como já demonstramos, a história venezuelana é marcada pela importância do petróleo, que, segundo o Fernando Coronil (2017), transformou o Estado no grande operador dos recursos naturais, possibilitando a construção do mito modernizante do Estado, ou seja, através do investimento de um bem natural, que pertence a todos os venezuelanos, o país atingira a modernização.

A intensificação da exploração petroleira no país no início do século XX acabou por transformar a matriz produtiva venezuelana, uma vez que, o até então país agrário, passou a receber investimentos estrangeiros. Assim, boa parte da mão de obra migrou do campo para a cidade em busca de melhores salários nas empresas de petróleo e na área de serviços, enquanto que a produção agrícola foi substituída pela importação de produtos básicos e industrializados. Dessa forma, a Venezuela se tornou um país duplamente dependente do 
mercado externo, já que necessitava vender petróleo e comprar todo tipo de produto, uma vez que a diversificação produtiva do país não consegue suprir a demanda nacional.

Nessa perspectiva, os EUA se tornaram os principais parceiros comerciais dos venezuelanos, atuando como comprador do petróleo e como fornecedor de produtos industrializados, em uma relação de proximidade diplomática e comercial entre os dois países. Durante os anos de 1980, em virtude dos empréstimos contraídos pelos governos venezuelanos para financiar o modelo político bipartidário vigente até então, e da crise capitalista que derrubou o preço do petróleo no mercado internacional, a Venezuela se alinhou com as diretrizes do Consenso de Washington para conseguir créditos e aportes financeiros para o pagamento da dívida junto ao Fundo Monetário Internacional. Dessa forma, o governo adotou medidas de austeridade, que adentraram a década de 1990 e que acabaram por rebaixar a já debilitada qualidade de vida dos venezuelanos.

A importância do petróleo venezuelano para os EUA e a forma como Chávez orientou seu discurso e sua agenda de políticas públicas foram as motivações que levaram os EUA a se alinharem com a oposição ao governo democraticamente eleito no país em 1998, mesmo que essa mesma oposição tenha sido a responsável por mergulhar o país em um caos administrativo e econômico que resultou na condição de miséria para grande parte dos venezuelanos.

A radicalização oposicionista se materializou no golpe de Estado contra Chávez em 2002. Na ocasião, uma parcela da burguesia nacional e dos militares, com apoio dos EUA (SALGADO, 2015), organizaram a ruptura democrática com a deposição do presidente, o cancelamento da Constituição aprovada em 1999 e do fechamento do Congresso, em uma clara demonstração do viés autoritário da oposição no país. No entanto, 48 horas depois de deposto, Chávez retornou ao cargo em função da pressão da população, que não apoiava os golpistas e exigia o retorno do presidente eleito.

O fracasso do golpe em 2002 demonstrou para os EUA que as táticas amplamente utilizadas durante os anos de 1960, 1970 e 1980 na América Latina para derrubar governos eleitos que não atendiam diretamente aos seus interesses não seria possível na Venezuela durante o século XXI.

Frente a tal situação, os EUA buscaram organizar a oposição venezuelana para conseguir derrubar o governo Chávez. Em outras palavras, se durante a Guerra Fria os EUA utilizavam os militares para desarticular a sociedade civil através da censura, da tortura, do 
fechamento de partidos políticos, de sindicatos, do movimento estudantil e dos movimentos de camponeses, dessa vez os EUA iriam organizar a sociedade civil.

No entanto, para tal estratégia, os EUA iriam adotar uma definição bastante específica de sociedade civil, sendo considerados apenas os apoiadores dos interesses estadunidenses, ou seja, os grupos sociais que não se alinhavam com os EUA não faziam parte da sociedade ${ }^{3}$.

Assim, o governo estadunidense utilizou de diversas instituições, como a Agência dos EUA para Desenvolvimento Internacional (USAID), o Escritório para Transição Internacional (OTI) e a The National Endowment for democracy (NED), por exemplo, para financiar e treinar a oposição venezuelana, com o objetivo de organizar os setores que eles reconheciam como "sociedade civil" venezuelana contra o governo Chávez, buscando derrotá-lo nas urnas, ou, se não fosse possível, utilizando de um manto democrático para retirá-lo do poder político através da pressão de setores oposicionistas, como a imprensa e parcelas da burguesia nacional e do capital internacional, em especial do financeiro.

Para Lars Schoutz, a política Externa dos EUA para a América Latina é movida pelo que o autor denomina "auto-interesse", ou seja, a necessidade de proteger os interesses estadunidenses na região. Dessa forma, após o controle econômico exercido e imposto aos governos latino-americanos durante os anos de 1980 e 1990 com os pacotes de reajustes econômicos neoliberais determinados pelo FMI, atualmente o objetivo da diplomacia norteamericana é controlar o sistema de justiça e a democracia dos países da América Latina através da atuação de agências como a NED e a USAID (2000, p.11).

No mesmo estudo, o autor apresenta quais seriam os novos desafios para os EUA na América Latina com o fim da Guerra Fria e da URSS. Assim, com maior controle hegemônico na região, a diplomacia estadunidense identificou novos desafios no continente, sendo eles o problema das drogas, a má administração financeira dos latino-americanos e as ditaduras, o que configura uma "hegemonia preventiva por parte dos EUA" (SCHOULTZ, 2000, p.13).

\footnotetext{
${ }^{3}$ Durante o século XX, quando os EUA apoiaram os golpes militares na América Latina, a organização da oposição aos governos democraticamente eleitos também era um expediente bastante comum, vide a Aliança para o Progresso, o Ipes e o Ibad no Brasil, por exemplo. No entanto, frente a radicalização das lutas de classe, em um ambiente marcado pela Guerra Fria, esse apoio a uma parcela específica da sociedade, geralmente setores da classe média, Igreja Católica, setores do Exército e Mídia, quando não era suficiente para derrubar um governo que não era simpático aos interesses dos EUA, estes incentivavam e apoiavam a instalação de ditaduras militares. A diferença para o que ocorre na Venezuela é que em 2002, o golpe militar não se concretizou, fazendo com que os EUA passassem a concentrar forças na oposição venezuelana.
} 
Os três pilares apontados como os norteadores da preservação dos interesses dos EUA na América Latina, ou seja, a defesa da Segurança Nacional, questões relacionadas à política interna e o desenvolvimento econômico, são encontrados na documentação analisada no presente trabalho, sendo que, como Schoultz aponta, as políticas para atingir os objetivos mudam, mas os interesses dos EUA são os mesmos.

De fato, através da documentação disponibilizada pelo Wikileaks, é possível perceber como o corpo diplomático estadunidense ajudou a OTI, a NED e a USAID a organizar a oposição venezuelana visando minar a credibilidade do governo Chávez e forma a interrompê-lo. O documento abaixo é exemplar para atestar tal questão. Desde o seu título Encontro de Deshazo com líderes de aposição do G-5, observa-se o estranhamento das funções diplomáticas com a espionagem e a conspiração. Preliminarmente é necessário esclarecermos quem era Peter Deshazo, então membro do corpo diplomático dos Estados Unidos, tendo servido como Subsecretário Assistente para o Hemisfério Ocidental e Representante Permanente Adjunto junto à Organização dos Estados Americanos (OEA) ${ }^{4}$.

As articulações para instrumentalizar a oposição ou mesmo definir suas estratégias é apontada no mesmo documento que versa sobre o encontro entre o embaixador e a oposição, mediado por Deshazo.

The Ambassador hosted a dinner for DAS DeSahazo with Julio Borges (Primeira Justicia), Juan Fernandez (Gente de Petroleo), Henrique Ramos Allup (Acción Democratica) and Enrique Salas Romer (Proyecto Venezuela) represented the G-5. Enrique Mendoza (COPEI) had accepted but did not attend ${ }^{5}{ }^{6}$

Este grupo oposicionista que protagonizará as articulações para fragilizar a representatividade do governo, cujos nomes são citados formalmente no documento despachado pela embaixada norte-americana em Caracas, foi denominado pelo corpo

\footnotetext{
${ }^{4}$ Durante sua carreira diplomática, dirigiu o Escritório de Diplomacia e Assuntos Públicos no Escritório de Assuntos para o Hemisfério Ocidental do Departamento de Estado e foi diretor de Assuntos do Hemisfério Ocidental no Escritório de Divulgação (antigo USIS). Ele serviu em embaixadas e consulados em La Paz, Medellin, Santiago, Cidade do Panamá, Caracas e Tel Aviv. Disponível em: https://www12.senado.leg.br/institucional/olddocumentos/institucional/SF/OAS/CONLEG/arquivos/seminarios-workshops/reuniao-tecnica-com-embaixadoramericano-peter-deshazo-relacoes-dos-eua-com-la-parcerias-estrategicas-com-o-brasil-estabilidade-regional-epolitica-de-defesa-paulo-springer-15-10-2009.

5 "O embaixador organizou um jantar para o DAS DeSahazo com Julio Borges (Primeira Justicia), Juan Fernández (Gente de Petroleo), Henrique Ramos Allup (Acción Democratica) e Enrique Salas Romer (Proyecto Venezuela) representaram o G-5. Enrique Mendoza (COPEI) aceitou, mas não compareceu."

${ }^{6}$ Doc. Confidential. no9521. Das Deshazo's meeting with g-5 apposition leaders 21/01/2004. Disponível em: https://wikileaks.org/plusd/cables/04CARACAS295_a.html
} 
diplomático G-5. Este encontro, realizado em 2004, momento em que ocorria o referendo revogatório $^{7}$ vinha a calhar, mesmo que fosse apenas para a obtenção de informações ${ }^{8}$.

No encontro, o embaixador e membros do corpo diplomático aconselham à oposição que "para alcançar a opinião pública com uma mensagem pública coordenada, coerente e positiva, apresentar um programa ou plano de ação e alcançar não apenas os oposicionistas, mas também os independentes e chavistas" ". Tal aconselhamento tinha como objetivo orientar a oposição a "organizar um plano que alcançasse não apenas os oposicionistas, mas também os independentes e chavistas" que votariam no referendo revocatório convocado com o intuito de abreviar o mandato de Chávez.

O referendo em questão foi o principal assunto tratado pela diplomacia dos EUA na Venezuela durante aquele ano de 2004, uma vez que era uma possibilidade real, e dentro da ordem institucional, da oposição retomar o poder político no país.

Outra reunião entre o corpo diplomático dos EUA e líderes da organização Súmate, que tinha a intenção de auditar o referendo, aconteceu em 16 de junho de 2004. Este encontro tratou da denúncia apresentada pelo governo Chávez contra os líderes da organização acusados de terem sidos financiados por instituições vinculadas aos EUA, o que punha em questão sua isenção na auditoria sobre a lisura do processo eleitoral. De fato, era o que alegara publicamente, para todo o país, o presidente venezuelano durante seu programa de $T V$ Alô Presidente $^{10}$ nos dias 8 e 15 de fevereiro.

SÚMATE leaders Maria Corina Machado and Alejando Plaz were charged on June 10 and 11 respectively with conspiracy to 'destroy the republican form of government' for accepting funds from the National Endowment for Democracy but have not been detained ${ }^{11}{ }^{12}$

\footnotetext{
${ }^{7}$ Referendo revocatório é uma ferramenta prevista na Constituição de 1999 e que foi convocado pela oposição em 2004 com o intuito de interromper o governo Chávez. No entanto, o resultado foi favorável ao chavismo, que se fortaleceu após a consulta eleitoral

${ }^{8}$ Outro relato sobre o encontro de funcionários da embaixada dos EUA com membros da oposição chavista pode ser encontrado em: Doc. Confidential - n¹0035. The "Tropical Unity" of the opposition. 12/02/2004. Disponível em: https://wikileaks.org/plusd/cables/04CARACAS533_a.html

9 “[...] to reach out to public opinion with a coordinated, coherent, and positive public message, put forward a program or plan of action, and reach out not only to oppositionists but also to independents and chavistas"

${ }^{10}$ Programa de TV apresentado por Hugo Chávez entre 1999 e 2002.

11 "Maria Corina Machado e Alejandro Plaz, líderes do Sumate, foram acusados nos dias 10 e 11 de junho, respectivamente, de conspiração para "destruir a forma republicana de governo" por aceitar fundos do Fundo Nacional para a Democracia, mas não foram detidos."

12 Doc.Confidential. $\mathrm{n}^{\mathrm{o}}$ 4987. Ambassador meets with Sumate leaders 16/06/2004. Disponível em: https://wikileaks.org/plusd/cables/04CARACAS1993_a.html
} 
Também as autoridades da Venezuela solicitaram à CIA informações sobre as relações entre o governo dos EUA e a Súmate, que se recusou a fornecê-las. No entanto, em telegrama despachado da embaixada estadunidense em Caracas, um funcionário da embaixada, cuja denominação genérica é "emboffs”, confirmam-se as ligações apontadas por Chávez.

Emboffs confirmed that the National Endowment for Democracy (NED) approved a grant to Súmate for $\$ 53,400$ in September 2003 to work on referendum and general electoral activities ${ }^{13} \cdot{ }^{14}$

O mesmo documento também confirma que a USAID/OTI financiou a Súmate ${ }^{15} \mathrm{em}$ agosto de 2003, com o intuito de fiscalizar o andamento e a organização do referendo revocatório, realçando que tal ação foi feita sem o conhecimento de Chávez. No caso de Corina Machado, fundadora da Súmate, essa se encontrou com o então presidente dos EUA Geogre W. Bush em 2005, onde se discutiu a polarização política venezuelana e a relação entre a Súmate e a NED. Conforme o consultor contratado pelo Congresso dos Estados Unidos, Mark Sullivan, de fato, a Súmate atuou como fornecedora de informações

On May 31, 2005, President Bush met with Maria Corina Machado, the founder of Súmate, Venezuelan civic group that was involved in the signature drive for the August recall referendum. The meeting exacerbated the already tense U.S-Venezuelan bilateral relations. Machado is facing charges in Venezuela for conspiring against the government by accepting U.S founding from National Endowment for Democracy for Súmate's activities up to the recall referendum. U.S officials and some Members of Congress have strongly defended the NED's activities in Venezuela and have criticized the Venezuelan government's efforts to intimidate the leaders of Sumate ${ }^{16} .17$

Outra evidência encontra-se na documentação que atesta que a embaixada estadunidense omitiu informações sobre ajuda de paramilitares colombianos à oposição, o que pode ser considerada uma estratégia para derrubada de Chávez. Em maio de 2004, quando o

\footnotetext{
${ }^{13 ،}$ "Emboffs confirmou que o Fundo Nacional para a Democracia (NED) aprovou uma doação para Sumate por US \$ 53.400 em setembro de 2003 para trabalhar em referendos e atividades eleitorais gerais."

${ }^{14}$ Doc. Confidential, nº563. Chavez accuses usg of funding "coupmongers". 26/02/2004. Disponível: https://wikileaks.org/plusd/cables/04CARACAS634_a.html/

${ }^{15}$ Outro documento em que a Sumate aparece como informante do Governo dos EUA na Venezuela pode ser encontrado em: Doc. Confidential n ${ }^{\circ} 9027$. Venezuela: Potential fraud in the appeals process 05/05/2004. Disponível em: https://wikileaks.org/plusd/cables/04CARACAS1507_a.html

${ }^{16}$ "Em 31 de maio de 2005, o presidente Bush se reuniu com Maria Corina Machado, fundadora da Sumate, grupo cívico venezuelano que esteve envolvido na assinatura do referendo revogatório em agosto. O encontro exacerbou as já tensas relações bilaterais EUA-Venezuela. Machado está enfrentando acusações na Venezuela por conspirar contra o governo aceitando a fundação dos EUA National Endowment for Democracy para as atividades de Sumate até o referendo revogatório. Autoridades dos EUA e alguns membros do Congresso defenderam fortemente as atividades do NED na Venezuela e criticaram os esforços do governo venezuelano para intimidar os líderes da Sumate."

${ }_{17}^{17}$ Disponível em: SULLIVAN. Mark. Venezuela: Political Conditions and U.S Policy. 2008. Congressional Research Service. Disponível em: https://file.wikileaks.org/file/crs/RL32488.pdf
} 
governo venezuelano deteve suspeitos de serem paramilitares colombianos com ligações com a oposição, com a intenção de darem um novo golpe militar, o corpo diplomático estadunidense, em documento confidencial despachado no dia 11 de maio de 2004, insinua que tinha conhecimento de tais forças militares e golpistas. Apesar de não confirmar as alegações governistas, o documento ${ }^{18}$ ressalta que "não podemos ignorar as alegações do governo (venezuelano) de que os colombianos faziam parte do plano anti-GOV",19.

Assim, tendo em mente a proximidade entre a oposição e os EUA, a não interferência da embaixada estadunidense, nem mesmo nos encontros entre as forças políticas em questão acerca da presença de paramilitares colombianos é um indício de que os EUA estariam dispostos, mais uma vez, a quebrar a ordem institucional democrática para retirar Chávez do poder. Anos depois, a presença de paramilitares colombianos na Venezuela é apontada por Julia Buxton que, em entrevista para a New Left Review em 2016, ressalta os problemas causados por tais presenças

This is an area where the Chavista government was very concerned about ties between Colombia's right-wing paramilitaries and the opposition, and a thriving across-border trade in smuggled goods ${ }^{20}$ (2016, p. 7).

A posição dos EUA em relação ao governo venezuelano pode ser explicada como reação as políticas públicas adotadas pelo governo Chávez, como o maior controle do Estado da extração do petróleo, a maior cobrança de royalties, e a utilização de parte desse aumento de recursos estatais para financiar programas sociais, o que melhorou as condições de vida dos venezuelanos mais pobres. Ora, tais políticas não iam ao encontro da agenda liberalizante proposta pelo governo dos EUA, cuja avaliação se expressa no título do documento: "Chávez dá ordens para colocar em marcha a Revolução"

Chávez remarks show a leader who is increasingly showing his commitment to shift Venezuela's political economic, and foreign policy orientation towards the left. Rhetoric aside, Chávez - unfortunately - has a strategic direction, and is aware that he faces obstacles and contradictions in his movement. ${ }^{21}$

\footnotetext{
${ }^{18}$ Doc. Confidential. $\mathrm{n}^{\circ}$ 7588. Chavez: Coup attempt averted with arrest of "paramilitaries. 11/05/2004. Disponível em: https://wikileaks.org/plusd/cables/04CARACAS1543_a.html

19 "we can't dismiss the GOV's allegations that the Colombians were part of anti-GOV plot"

20 "Esta é uma área em que o governo Chavista estava muito preocupado com os laços entre os paramilitares de direita e a oposição da Colômbia, e um comércio na fronteira de mercadorias contrabandeadas."

21، As observações de Chávez mostram um líder que está cada vez mais mostrando seu compromisso de mudar a política econômica da Venezuela e a orientação da política externa para a esquerda. Retórica à parte, Chávez infelizmente - tem uma direção estratégica, e sabe que enfrenta obstáculos e contradições em seu movimento". Doc. Confidential. $\mathrm{n}^{\circ} 12763$. Chavez gives marching orders for the Revolution. 23/12/2004. Disponível em: https://wikileaks.org/plusd/cables/04CARACAS3928_a.html
} 
Frente à organização e ao fortalecimento do governo chavista os EUA buscaram incentivar outras iniciativas da oposição, em particular, a ação de ONGs na Venezuela. No mesmo documento confidencial de 30 de agosto de 2004, o corpo diplomático norteamericano aponta ainda que "teremos mais impacto, no entanto, se pudermos expressar nossas opiniões em conjunto com outros países e ONGs". ${ }^{22}$

Já em fevereiro de 2004 Chávez questionava as ligações entre as ONGs e a o governo dos EUA, em especial a NED. Na ocasião, as ONGs Súmate, Provea, Red de Apoio entre outras, foram acusadas de receberam financiamento estrangeiro, em particular dos EUA. ${ }^{23}$

Apesar de negarem as acusações, em telegrama confidencial do dia 20 de fevereiro de 2004, a embaixada estadunidense confirma o repasse de verbas e que estas organizações são canais efetivos de auxílio na organização da oposição: "todas as organizações nomeadas por Chávez recebem financiamento de uma variedade de fontes estrangeiras e declaram que seu financiamento é informação pública."24

In October of 2005, the Pan American Development Foundation (PADF) began implementation of a USAID/OTI funded project to develop a grants program to support watchdog organizations. Although the Bolivarian "Revolution" is failing its citizens in many ways, there are few reputable organizations dedicated to documenting this failure. PADF has funded 9 NGOs to support projects focusing on documenting and reporting on the BRV's failures, namely: judicial independence, the right of association, violent crime, the prison situation, self-censorship of the media, harassment of journalists, women's political rights, human rights, and BRV support to micro-entrepreneurs. ${ }^{25}$

\footnotetext{
22 “[...] we will have for more impact, however, if we can voice our opinions in concert with other countries and NGOs." Doc. Confidential. n¹2763. Chavez gives marching orders for the Revolution. 23/12/2004. Disponível em: https://wikileaks.org/plusd/cables/04CARACAS3928_a.html

${ }^{23}$ No documento confidencial intitulado NGOs cite worrisome huma rights partterns, do dia 4 de outubro de 2004, é relatado o encontro de representantes de diversas ONGs com membros da embaixada dos EUA. Dentre os presentes na reunião estavam presentes membros da Igreja Católica, de grupos de juristas e membros da imprensa oposicionista. Verificar. Doc. Confidential. $\mathrm{n}^{\circ}$ 8999. NGOS CITE WORRISOME HUMAN RIGHTS PATTERNS. 04/10/2007. Disponível em: https://wikileaks.org/plusd/cables/07CARACAS1969 a.html.

${ }^{24}$ All of the organizations named by Chavez receive funding from a variety of foreign sources and state that their financing is public information". Doc. Confidential n5131. Chavez Takes aim at human rights organization. 20/02/2004. Disponível em: https://wikileaks.org/plusd/cables/04CARACAS612 a.html. A relação entre o governo dos EUA e as ONGs na Venezuela também pode ser verificado em documento confidencial do dia 26 de janeiro de 2007, quando a embaixada estadunidense, juntamente com a Fundação de Desenvolvimento Pan Americano (PADF), iniciaram um programa para financiar uma série de ONGs para produzir relatórios criticando o governo venezuelano. Verificar: Doc.Confidential. $\mathrm{n}^{\circ} 9345$. USAID/OTI WATCHDOGS START TO SHED LIGHT. 26/01/2007. Disponível em: https://wikileaks.org/plusd/cables/07CARACAS175 a.html 25. "Em outubro de 2005, a Fundação Pan-Americana para o Desenvolvimento (FUPAD) iniciou a implementação de um projeto financiado pela USAID / OTI para desenvolver um programa de subsídios para apoiar organizações de vigilância. Embora a "Revolução" Bolivariana esteja falhando de várias formas em seus cidadãos, existem poucas organizações respeitáveis dedicadas a documentar essa falha. A PADF financiou ONGs para apoiar projetos focados em documentar e relatar os fracassos da BRV, a saber: independência judicial, direito de associação, crime violento, situação carcerária, autocensura da mídia, perseguição de
} 
Tratava-se, na realidade, de atestar que as instituições democráticas venezuelanas não estavam sendo respeitadas, pois haveria impedimento ao funcionamento independente da esfera jurídica, de direito de associação, coerção à mídia, perseguição a jornalistas, negação de direitos políticos às mulheres e demais direitos humanos e apoio da "BRV à microempresários". No interior disso mesclaram a violência social expressa em crimes violentos e insinuam a "situação carcerária"

\section{A Organização da Sociedade Civil e as ONGs}

Para o corpo diplomático dos EUA, as ONGs eram de suma importância para a organização da sociedade civil venezuelana, sendo que a definição de sociedade civil estava restrita as forças oposicionistas. Qualquer iniciativa da oposição em se organizar contra o governo era bem-vinda pelos EUA, principalmente no contexto de campanha para o referendo revogatório.

Assim, por exemplo, quando a oposição, articulada na Coordinadora Democrática (CD), que reunia um conjunto de partidos, começa a realizar as denominadas assembleias cidadãs, a Embaixada estadunidense em Caracas informa seu governo que este era um mecanismo democrático e constitucional utilizado pela oposição para vencer Chávez nas urnas.

Desde o título do documento em que tal consideração aparece, “Assembleias cidadãs: Sociedade civil se organiza", a embaixada norte-americana chama a atenção para importância de tal prática e que essa estava de acordo com o artigo 70 da Constituição venezuelana

The Asambleas are valuable to the $\mathrm{CD}$ as a mean to publicize and generate grassroots support for its campaign to recall Chavez. While the Asambleas tend to only attract those individuals who were already faithful to the opposition's agenda, they still provide a legion of willing volunteers who will take the campaign to the streets to rally participation for the recall effort. ${ }^{26}$

jornalistas, direitos políticos das mulheres, direitos humanos e apoio de BRV a microempresários." Doc. Confidential. n'5131. Chavez Takes aim at human rights organization. 20/02/2004. Disponível em: https://wikileaks.org/plusd/cables/04CARACAS612 a.html.

26 “As Assembleias são valiosas para o CD como forma de divulgar e gerar apoio de base para sua campanha para retirar Chávez. Enquanto as Assembleias tendem a atrair apenas aqueles indivíduos que já eram fiéis à agenda da oposição, ainda há uma legião de voluntários dispostos a levar a campanha às ruas para conquistar a participação para o esforço de recall." Doc. Confidential. nº4576. Citizens assemblies: civil society gets organized. 28/07/2004. Disponível em: https://wikileaks.org/plusd/cables/04CARACAS2389_a.html 
Em contrapartida, quando se tratava de manifestações pro-chavistas, como, por exemplo, a da organização comunal de forças chavistas, estas eram desqualificadas por não se configurarem como "sociedade civil."

O chavismo se manifestava em especial dentro dos barrios, que, desde o final da década de 1980, vinha se organizando autonomamente, ou seja, fora das diretrizes e das instituições do Estado adotando uma perspectiva mais autônoma. Tal estratégia foi utilizada para combater as debilidades inerentes de um Estado rentista em um país de capitalismo atrasado, ou seja, as rendas do petróleo acabavam por fluir para as mãos da burguesia nacional e internacional, legando para grande parte da população uma situação de miséria. Dessa forma, práticas comunais de auto-organização, que foram de extrema importância para garantir a democracia venezuelana durante o golpe de 2002, não são consideradas pelos EUA como partes da "sociedade civil organizada": Thus far, opponents of President Hugo Chávez have been the only sector of the population to invoke the constitutional right to organize Asambleas de Ciudadanos ${ }^{27}$.

No documento de 2008, produzido por Mark Sullivan para o Congresso dos EUA, intitulado Venezuela: Political Conditions and U.S Policy, no qual Sulivan faz uma retrospectiva ano a ano das condições políticas venezuelanas a partir de 2002, é possível perceber a preocupação do governo dos EUA com a organização comunal incentivada durante o governo Chávez:

Still other critics of Chávez believed that he was trying to politicize the educational system by making changes to school curriculums. They fear Chávez call for his followers to form political cells in schools, hospitals, and business in order to support his revolution and believe that such groups, known as Bolivarian Circles, could mirror Cuba's controversial neighborhood committees. ${ }^{28}$

Como é possível perceber pelo trecho destacado acima, as organizações de bairro que emergem desde os anos de 1980 não são consideradas pelo corpo diplomático dos EUA quando este analisa a atuação da população de acordo com organizações sociais de base (educação, saúde e mesmo negócios). Desqualificam, assim uma grande gama de iniciativas de participação que são expressões da democracia direta que se praticava no país antes mesmo

\footnotetext{
27 "Até agora, os opositores do presidente Hugo Chávez foram os únicos setores da população a invocar o direito constitucional de organizar Asambleas de Ciudadanos." Doc. Confidential. nº576. Citizens assemblies: civil society gets organized. 28/07/2004. Disponível em: https://wikileaks.org/plusd/cables/04CARACAS2389_a.html ${ }^{28}$ SULLIVAN. Mark. Venezuela: Political Conditions and U.S Policy, 2008. Congressional Research Service. Disponível em: https://file.wikileaks.org/file/crs/RL32488.pdf
} 
do governo Chávez, e que ganharam força após o golpe de 2002, como coloca Ciccarielo Maher:

Again, this spontaneity both reflected and contributed to existing organized currents: in the tension running up to the coup, popular forces in the barrios and the nascent popular councils came together to form what was called the Revolutionary Popular Assembly (APR), which participant Gonzalo Gómez later describer to me as an 'articulation of popular power' ${ }^{29}$ (MAHER, 2013, p.172).

Tal postura por parte dos EUA pode ser entendida como uma forma de imposição do neoliberalismo na Venezuela. Se entendermos que o neoliberalismo é mais do que um sistema econômico, mas também uma "razão do mundo" (DARDOT; LAVAL, 2016), que tenta impor uma nova racionalização baseada na concorrência às formas de convivência dos indivíduos com eles mesmos e com os outros, as formas de organização coletivas e comunais são tidas como incompatíveis com a modernidade capitalista.

O neoliberalismo não destrói apenas regras, instituições, direitos. Ele também produz certos tipos de relações sócias, certas maneiras de viver, certas subjetividades. Em outras palavras, com o neoliberalismo, o que está em jogo é nada mais nada menos que a forma de nossa existência, isto é, a forma como somos levados a nos comportar, a nos relacionar com os outros e com nós mesmos. O neoliberalismo define certa norma de vida nas sociedades ocidentais e, para além dela, em todas as sociedades que as seguem no caminho da "modernidade" (DARDOT; LAVAL, 2016, p.16).

Assim, as consecutivas vitórias eleitorais de Chávez, juntamente com as debilidades políticas da oposição venezuelana, levaram os EUA a treinar os opositores de Chávez para que conseguissem melhorar suas condições de vitória eleitoral. Dessa forma, o National Democratic Institute (NDI) e o International Republican Institute (IRI), buscaram providenciar

[...] training to political parties in 1) execution of electoral campaigns with emphasis on developing strategies and communicating party platforms effectively to voters; and 2) observation of electoral process, focused on assessment, reporting, and establishment of a volunteer trainer network. ${ }^{30}$

\footnotetext{
29 "Mais uma vez, essa espontaneidade refletia e contribuía para as correntes organizadas existentes: na tensão que se estendia ao golpe, forças populares nos bairros e os nascentes conselhos populares se uniram para formar o que se chamava Assembleia Popular Revolucionária (APR), que participava Gonzalo. Gómez depois descreveme como uma "articulação do poder popular"

30 “[...] Treinamento para partidos políticos em 1) execução de campanhas eleitorais com ênfase no desenvolvimento de estratégias e comunicação eficaz de plataformas partidárias aos eleitores; e 2) observação do processo eleitoral, com foco na avaliação, elaboração de relatórios e estabelecimento de uma rede de treinamento de voluntários." Doc. Unclassified. nº443. Human rights strategy for Venezuela. 04/02/2004. Disponível em: https://wikileaks.org/plusd/cables/04CARACAS425_a.html
} 
O documento citado se intitula Estratégia de Direitos Humanos para a Venezuela, e como é possível perceber, os EUA tinham a intenção de organizar a oposição para os colocar em melhores condições de vencer pleitos, buscando otimizar as campanhas, as estratégias de comunicação e o processo eleitoral. Para tal, foi destinado uma soma de mais de 700 mil dólares para "fortalecer a sociedade civil e as instituições democráticas" ${ }^{31}$. Em outro documento, datado do dia 11 de fevereiro de 2004 é relatado com detalhes, a ação da USAID/OTI na Venezuela, demonstrando como os EUA buscavam interromper o governo Chávez através de ações consideradas em defesa da organização da sociedade civil e da democracia.

USAID's office of transition initiatives (OTI) began its Venezuela program in November 2002 to support the primary USG goal of supporting democracy and democratic solution to Venezuela's crisis. USAID'S overall goal in Venezuela is to support a political process that is democratic, constitutional, electoral and peaceful ${ }^{32}$.

Para tal, instituições estadunidenses receberam financiamento para atuar na Venezuela em conjunto com a oposição. Segundo o documento, as instituições beneficiadas foram a The National Institute of International Affairs, The International Republican Institute, The Carter Center, Development Alternatives, e uma série de "organizações da sociedade civil venezuelana",33.

Além da já mencionada quantia destinada ao fortalecimento da sociedade civil, os EUA investiram outros 450 mil dólares para o aprofundamento do treinamento político da oposição e o repasse de 550 mil dólares para a organização de coalizões políticas, de 285 mil dólares para o Centro Carter e de um total de 3,5 milhões de dólares para organizações venezuelanas $^{34}$.

Conforme sintetiza Sulivan no já citado documento: Venezuela: Political Conditions and U.S Policy, apenas no ano de 2007 o orçamento direto para as ações dos EUA na Venezuela foi de 10 milhões de dólares e, a considerar outro informe, tal transferências de

\footnotetext{
31 "[...] strengthen civil society and democratic institutions"

32 "O Escritório de Iniciativas de Transição (OTI) da USAID iniciou seu programa na Venezuela em novembro de 2002 para apoiar a meta principal do governo dos EUA de apoiar a democracia e a solução democrática para a crise da Venezuela. O objetivo geral da USAID na Venezuela é apoiar um processo político que seja democrático, constitucional, eleitoral e pacífico." Doc. Unclassified. $\mathrm{n}^{\circ} 31401$. Update on the USAID/OTI Venezuela program. 11/02/2004. Disponível em: https://wikileaks.org/plusd/cables/04CARACAS501_a.html

${ }^{33}$ Idem

${ }^{34}$ Idem
} 
recursos não findou neste ano, pois em 2009, o orçamento direto para as instituições da "sociedade civil venezuelana chega a mais de sete milhões de dólares. ${ }^{35}$

Tais recursos foram repassados para o International Republican Institute (IRI) pertencente ao Partido Republicano, responsável pela organização do "Camping treining scholls $^{36 \%}$. Apesar do documento em questão colocar que os cursos estavam abertos para todos, oposição e situação, os módulos foram ofertados em várias partes do país, em especial nos Estados e regiões controlados por partidos e políticos opositores, como Zulia, Táchira e Merida. $^{37}$

Outra instituição que aparece na documentação ${ }^{38}$ é o "think tank Cedice" (Center for the Dissemination of Economic Information), que ofereceu consultoria para a CD com o objetivo de viabilizar "o desenho, o planejamento e a execução das campanhas eleitorais", em uma estratégia que aparece no informe intitulado Oposição lança "Plano de consenso nacional". 39

USAID is also supporting two cooperative agreements with the International Republican Institute (IRI). The first, for $\$ 450,00$, is to provide training to political parties on the design, planning, and execution of electoral campaigns. This is being done through "campaign training schools" targeting campaign managers. The emphasis is on the development of viable campaign strategies and effectively communication party platforms to voters. Divided into six two-day modules, the training is being offered in five regional centers. ${ }^{40}$

O Cedice chegou a elaborar um plano para a transição, tamanha era a certeza do sucesso de suas investidas, o qual foi denominado Plan Consenso Pais, um "guia para um governo de transição" na Venezuela.

\footnotetext{
${ }^{35}$ Doc. Confidential ${ }^{\circ}$ 5972. Request for additional funds to help strengthen local governments and civil society groups. 27/03/2009. Disponível em: https://wikileaks.org/plusd/cables/09CARACAS404_a.html

${ }^{36}$ Doc. Unclassified. $n^{\circ} 31401$. Update on the USAID/OTI Venezuela program. 11/02/2004. Disponível em: https://wikileaks.org/plusd/cables/04CARACAS501_a.html

37 BUXTON, Julia. Venezuela after Chávez. New Left Review, May/June 2016. Disponível em: https://newleftreview.org/II/99/julia-buxton-venezuela-after-chavez.

${ }^{38}$ Doc. Confidential. $\mathrm{n}^{\circ}$ 10445. Opposition launches "National consensus plan. 15/07/2004. Disponível em: https://wikileaks.org/plusd/cables/04CARACAS2248_a.html

${ }^{39}$ A relação entre a CEDICE, a oposição venezuelana, o governo dos EUA e a formação de uma rede de tinktanks conservadores na América Latina é explicitada no texto disponível em: https://theintercept.com/2017/08/11/esfera-de-influencia-como-os-libertarios-americanos-estao-reinventando-apolitica-latino-americana/

40 “USAID também está apoiando dois acordos de cooperação com o Instituto Republicano Internacional (IRI). O primeiro, por US $\$ 450$ mil, é para fornecer treinamento aos partidos políticos sobre o design, planejamento e execução de campanhas eleitorais. Isso está sendo feito por meio de "escolas de treinamento de campanha" direcionadas aos gerentes de campanha. A ênfase está no desenvolvimento de estratégias de campanha viáveis e na efetiva comunicação de plataformas partidárias aos eleitores. Dividido em seis módulos de dois dias, o treinamento está sendo oferecido em cinco centros regionais.". Doc. Unclassified. $\mathrm{n}^{\circ} 31401$. Update on the USAID/OTI Venezuela program. 11/02/2004. Disponível em:
} https://wikileaks.org/plusd/cables/04CARACAS501_a.html 
CEDICE reports, made public through FOIA request by Chavez supporters in the U.S., show that Diego Bautista Urbaneja met with CEDICE leaders. In addition, CEDICE asserts that the CD commission did use the consensus document as a "basis" for its Plan Consenso Pais ${ }^{41}$.

A Cedice é vinculada à Atlas Network, uma organização de caráter libertária que recebe financiamento de bilionários como os irmãos Koch e da NED, que há décadas busca enfraquecer os partidos de esquerda e movimentos sociais na América Latina e em outras regiões do mundo através do financiamento à ONGs e think tanks com o objetivo de realizar uma intervenção branca em diversos países.

Além da Venezuela, onde a Atlas conta como um de seus associados a Cedice, essa rede também tem como filiados movimentos como o Movimento Brasil Livre (MBL), Instituto Millenium e Instituto Liberal no Brasil, a Fundación Pensar na Argentina, a Eléutera Foundation em Honduras e outras tantas espalhadas pela América Latina que participaram ativamente de movimentos políticos que resultaram em troca de governo e na derrubada de presidentes progressistas.

Uma vez que a intervenção branca é bem sucedida, os membros desses institutos e ONGs acabam sendo convidados a participar do novo governo e do desenho de um plano de governo ultra neoliberal com o objetivo de derrubar as conquistas sociais e os direitos sociais dos trabalhadores, além de promoverem uma série de medidas com o intuito de facilitar a financeirização e a privatização nos países que passaram por tais processos, como Brasil e Argentina, por exemplo ${ }^{42}$.

Em 2008, a continuidade da síntese feita por Sulivan sobre tais financiamentos à NED, à Súmate, à Coordenadoria Democrática e a Cedice, esclarece que

The NED asserts that all of the Venezuelan programs that it funds operate on a nonpartisan basis. It maintains that Súmate, which received a grant of $\$ 53,400$ in September 2003, mobilized a citizen campaign to monitor the signature collection process and that the money was used to encourage citzens to participate. NED officials also assert that they did not fund the Democratic Coordinator for the development of its July 2004 consensus platform. The NED points out that it did fund a consensus building project in 2002 for one of the NED's core institutions, the Center for International Private Enterprise (CIPE). For the project, CIPE partnered with a Venezuelan group, the Center for the Dissemination of Economic Information

\footnotetext{
41 “Os relatórios do CEDICE, divulgados por solicitação da FOIA por apoiadores de Chávez nos EUA, mostram que Diego Bautista Urbaneja se reuniu com os líderes do CEDICE. Além disso, o CEDICE afirma que a comissão do CD utilizou o documento de consenso como uma "base" para seu Plano Consenso Pais." Doc. Unclassified. $\mathrm{n}^{\circ} 31401$. Update on the USAID/OTI Venezuela program. 11/02/2004. Disponível em: https://wikileaks.org/plusd/cables/04CARACAS501_a.html

42 Mais informações sobre a Atlas: https://theintercept.com/2017/08/11/esfera-de-influencia-como-os-libertariosamericanos-estao-reinventando-a-politica-latino-americana/
} 
(CEDICE) to work with several Venezuelan nongovernmental organizations and the business sector for the development of a broad-based consensus ${ }^{43} .44$

A preocupação da oposição e, particularmente dos EUA, com a "sociedade civil" pode ser explicada pela organização apresentada por setores populares, muitos deles alinhados com o chavismo. Tal inquietação transparece no documento confidencial, datado do dia 10 de dezembro de 2004, descrevendo as impressões da diplomacia estadunidense acerca da visita de um funcionário da embaixada a um mercado e a uma escola bolivariana em Caracas.

$\mathrm{Na}$ visita, além de apontar problemas como o trabalho infantil e o tráfico de drogas, o funcionário dos EUA reconhece que "os bens para a venda subsidiados pelo governo pareciam ser de boa qualidade e supostamente com preços mais baixos do que o setor privado", ${ }^{45}$ além de fazer referência aos mercados subsidiados pelo governo, os Mercal. ${ }^{46}$

No mesmo documento, sobre as escolas bolivarianas, a descrição é de que os prédios são bem equipados e de que tais escolas recebem mais verbas que outras instituições de ensino. Chamou a atenção do diplomata os valores ensinados nas escolas bolivarianas, sendo reportados da seguinte maneira: "Os valores incluíram participação, cooperação, responsabilidade e solidariedade" ${ }^{, 47}$. Outro disse: "Eu sou honesto porque minha família, escola e meio ambiente me ajudam a me esforçar" ${ }^{, 48}$.

Uma das atividades presenciadas pelo funcionário estadunidense, segundo seu próprio relato, foram alunos da sexta-série praticando letra de mão copiando artigos da Constituição Bolivariana. Outro aspecto que aparece no documento é a decoração das salas de aula, onde

\footnotetext{
${ }^{43}$ “NED afirma que todos os programas venezuelanos financiados operam numa base apartidária. Sustenta que a Sumate, que recebeu uma concessão de US $\$ 53.400$ em setembro de 2003, mobilizou uma campanha cidadã para monitorar o processo de coleta de assinaturas e que o dinheiro foi usado para incentivar os cidadãos a participar. As autoridades do NED também afirmam que não financiaram a Coordenadoria Democratica para o desenvolvimento de sua plataforma de consenso em julho de 2004. O NED aponta que financiou um projeto de construção de consenso em 2002 para uma das principais instituições do NED, o Centro de Empresas Privadas Internacionais (CIPE). Para o projeto, o CIPE fez uma parceria com um grupo venezuelano, o Centro de Difusão de Informações Econômicas (CEDICE) para trabalhar com várias organizações não-governamentais venezuelanas e o setor empresarial para o desenvolvimento de um amplo consenso."

44 SULIVAN, Mark. Venezuela: Political Conditions and U.S. Policy. 10/10/2008. Disponível em: https://wikileaks.org/wiki/CRS:_Venezuela:_Political_Conditions_and_U.S._Policy,_October_10,2008

45 "The government-subsidized goods for sale appeared to be of good quality and reportedly priced lower than the private sector",

${ }^{46}$ Doc. Confidential No6352. Visit to mass market and Bolivarian school.. 10/12/2004. Disponível em: https://wikileaks.org/plusd/cables/04CARACAS3817_a.html

47 "The values included participation, cooperation, responsibility, and solidarity. Another said, 'I'm honest because my family, school, and environment help me train myself'.

48 “[...] Os valores incluíram participação, cooperação, responsabilidade e solidariedade. Outro disse: "Eu sou honesto porque minha família, escola e meio ambiente me ajudam a melhorar"
} 
várias bandeiras de diferentes países enfeitam as paredes. No entanto, a bandeira dos EUA não figura entre elas.

Poloff also visited a Bolivarian School, with grades first through sixth, where ANM holds workshops. Bolivarian Schools receive special funding and offer breakfast, lunch and a snack, a rarity among public schools. The buildings had been remodeled and were well maintained, in stark contrast to the surrounding rundown slum. The students wore uniforms and seemed to have well supplied classrooms. The school's interior was decorated with references to the children's rights contained in the Bolivarian Constitution.

6. (U) The school's assistant principal said the GOV also used the facility for other educational programs, including Mission Robinson (literacy), Mission Ribas (high school), and Mission Sucre (college). Poloff observed several television sets with video players in the classrooms. In a sixth-grade class, the students were practicing handwriting by copying articles of the Bolivarian Constitution out of the trademark blue booklets often flashed by President Hugo Chavez. An exhibition entitled "Traveling Through The Countries Of The World" contained a stylized globe with a projection that occluded North America. Flags of the nations included Cuba, Iraq, and China, but not the United States. Poloff also noticed the older classes were supplied with the Bolivarian libraries, sets of books produced last year in cooperation with the Government of $\mathrm{Cuba}^{49}$.

Tais práticas educacionais adotadas pelo governo bolivariano e componentes da Missões ${ }^{50}$, foram consideradas uma forma de, sutilmente, "injetar ideologia" ${ }^{51}$ nos alunos, ou seja, os pressupostos defendidos pelo governo venezuelano são opostos aos considerados ideais pelos EUA, em especial no concernente ao livre mercado e às práticas de educação existentes nas escolas bolivarianas.

Ao adotar posturas que, de alguma forma, incentivam a prática comunitária, a construção de uma identidade venezuelana autônoma, com a presença do Estado como fiador de tal empreendimento, o governo chavista não se alinhava com os ideais de ultra

\footnotetext{
49 "Poloff também visitou uma Escola Bolivariana, com turmas de $1^{\circ}$ ao $6^{\circ}$ anos, onde a Asociacion Nina Madre (ANM) realiza oficinas. As escolas bolivarianas recebem financiamento especial e oferecem café da manhã, almoço e lanche, uma raridade entre as escolas públicas. Os prédios haviam sido reformados e estavam bem conservados, em contraste com a favela do entorno. Os estudantes usavam uniformes e pareciam ter salas de aula bem supridas. O interior da escola foi decorado com referências aos direitos das crianças contidos na Constituição Bolivariana. Um quadro de avisos dizia: "Juntos, com a família e a escola, estamos resgatando nossos valores". Os valores incluíram participação, cooperação, responsabilidade e solidariedade. Outro disse: "Eu sou honesto porque minha família, escola e meio ambiente me ajudam a me treinar".

6. (U) O diretor assistente da escola disse que o GOV também usou a instalação para outros programas educacionais, incluindo Mission Robinson (alfabetização), Mission Ribas (ensino médio) e Mission Sucre (faculdade). Poloff observou vários aparelhos de televisão com players de vídeo nas salas de aula. Em uma turma do sexto ano, os estudantes praticavam caligrafia, copiando artigos da Constituição Bolivariana dos livretos azuis de marca registrada, frequentemente exibidos pelo presidente Hugo Chávez. Uma exposição intitulada "Viajando pelos países do mundo" continha um globo estilizado com uma projeção que ocorria na América do Norte. As bandeiras das nações incluíam Cuba, Iraque e China, mas não os Estados Unidos. Poloff também notou que as classes mais antigas eram abastecidas com as bibliotecas bolivarianas, conjuntos de livros produzidos no ano passado em cooperação com o governo de Cuba."

${ }^{50}$ Missões são os diversos programas sociais colocados em prática pelo governo Chávez na Venezuela.

${ }^{51}$ Doc. Confidential. №6352. Visit to mass market and Bolivarian school. 10/12/2004. Disponível em: https://wikileaks.org/plusd/cables/04CARACAS3817_a.html
} 
individualismo e meritocracia proposto pelo ideário neoliberal, uma vez que buscou adotar políticas que

[...] estivessem por meta a reversão do processo de fragmentação social [...] graças justamente à ascensão das práticas neoliberais e do espírito neoliberal que as acompanha, espírito do cada um por si, do individualismo exacerbado, da demonização do Estado e dos movimentos sociais, da esterilização da força política dos sindicatos e assim por diante, espírito que a política econômica objetivo em transformações concretas e a mídia se encarrega de difundi-lo como se fosse uma coisa absolutamente natural (PAULANI, 2008, p. 69).

Além das escolas bolivarianas já citadas, em documento confidencial do dia 17 de junho de 2004, a embaixada dos EUA em Caracas busca analisar a situação social na Venezuela. Dentre os aspectos levantados pela diplomacia estadunidense estão os índices de pobreza e de extrema pobreza, que segundo dados do Instituto Nacional de Estatística, estavam em crescimento. Tais dados devem ser lidos no contexto de golpe de 2002, das greves e do locaute promovidos pela oposição que prejudicaram a economia nacional, causando o aumento da pobreza. No entanto, os membros da embaixada dos EUA consideram que um receituário neoliberal poderia resolver os problemas sociais venezuelanos:

Exchange controls which keep interest rates low and money inside the country, combined with wide open fiscal policy are likely to increase the "feel good" factor. The various social welfare missions will continue to be relentlessly publicized, whatever their real-world impact may be. ${ }^{52}$

Assim, mesmo que Chávez não tivesse se comprometido completamente com a transformação social, o fato de que não se alinhava totalmente com o neoliberalismo, aumentando a presença do Estado, incentivando organizações sociais e a participação na gestão de políticas públicas, fez com que os EUA o entendesse como uma ameaça a seus interesses e à América Latina.

\begin{abstract}
Não podemos esquecer, todavia, que não foi apenas a força das ideias neoliberais que garantiu sua hegemonia. Elas se impuseram a partir do enfraquecimento das doutrinas de esquerda e do desabamento de qualquer alternativa ao capitalismo. Elas se afirmaram sobretudo num contexto de crise dos antigos modos de regulação da economia capitalista, no mento em que a economia mundial era afetada pelas crises do petróleo. Isso explica por que, diferentemente dos anos 1930, a crise do capitalismo fordista resultou numa saída favorável não a menos capitalismo, mas, sim, a mais capitalismo. O principal tema dessa guerra ideológica foi a crítica do Estado como fonte de todos os desperdícios e freio à prosperidade (DARDOT; LAVAL, 2016, p. 207).
\end{abstract}

\footnotetext{
52 "Controles cambiais que mantêm as taxas de juros baixas e o dinheiro dentro do país, combinados com uma política fiscal aberta, tendem a aumentar o fator "sentir-se bem". As várias missões de bem-estar social continuarão a ser incansavelmente divulgadas, qualquer que seja seu impacto no mundo real.”. Doc. confidential $\mathrm{n}^{\circ}$ 10682. No Progress on poverty under Chávez. 17/06/2004. Disponível em:
} https://wikileaks.org/plusd/cables/04CARACAS2003_a.html 
Dessa forma, a construção da hegemonia neoliberal proposta pelos EUA passa por uma crítica a ação do Estado, o entendendo como ineficiente e corrupto, como um fato de limitação da liberdade individual, que levaria a prosperidade. Assim, iniciativas como as Missões chavistas que, através do Estado, buscavam melhorar as condições de vida da população, são entendidas como um entrave, já que exime os indivíduos de suas responsabilidades com a sociedade, uma vez que, como o Estado é provedor, este não precisa cumprir responsabilidades como procurar trabalho, cuidar dos filhos, prevenir doenças e etc. Assim, a razão neoliberal inverte as causas dos problemas sociais, que deixa de ser o capitalismo e passa a ser o Estado. Reside nesse discurso a defesa do Estado mínimo feita pelos ideólogos neoliberais (DARDOT; LAVAL, 2016).

Seguindo essa trilha, o neoliberalismo transforma a questão do papel do Estado no âmbito social em uma questão moral, transferindo para o Estado social a capacidade de destruir

[...] as virtudes da sociedade civil: a honestidade, o sentido do trabalho bem feito, o esforço pessoal, a civilidade, o patriotismo. Não é o mercado que destrói a sociedade civil com sua 'sede de lucro', porque ele não poderia funcionar sem essas virtudes da sociedade civil, é o Estado que que corrói as molas da moralidade individual (DARDOT; LAVAL, 2016).

Tal visão doutrinária e ideológica adotada pelos EUA pode ser percebida no documento despachado em janeiro de 2009, onde é colocado que os investimentos privados na Venezuela não acontecem porque existe o temor de nacionalizações por parte do Estado, sendo que tal política estatal leva a uma diminuição do fluxo de capitais o que, aliado à queda do preço do petróleo, resulta em crise econômica e social no país. Com esse diagnóstico, o governo dos EUA não leva em consideração uma série de variantes estruturantes que explicam o papel e a relação do Estado e a sociedade em um país como a Venezuela, apenas traça relações econômicas entre investimento e ação estatal no sentido de facilitar ou não tais investimentos ${ }^{53}$.

A ênfase em uma política onde o Estado ocupa um papel central não apenas na transferência de renda e no oferecimento de serviços básicos, mas também no sentido de criar uma consciência comunitária, baseada em pressupostos distintos dos defendidos e impostos pela lógica neoliberal do mercado e da concorrência, levou os EUA a impor um discurso que

\footnotetext{
${ }^{53}$ Doc. Confidential n ${ }^{\circ} 16351$. Venezuelas's 2009 economic outlook: Grim to Dire. 22/01/2009. Disponível em: https://wikileaks.org/plusd/cables/09CARACAS87_a.html
} 
prega o Estado como ineficiente, incapaz de gerir e oferecer os serviços quer se propõem, seja porque é corrupto ou pelo fato de ser ideologicamente orientado.

Nessa lógica, seria necessário que o Estado criasse um ambiente social e econômico propício para os investimentos privados e para a atuação de ONGs financiadas por instituições estadunidenses que, em última instância, em um país como a Venezuela, acabariam por competir com o próprio Estado em vários ambientes, entre eles os barrios chavistas, principais redutos do eleitorado e dos apoiadores da Revolução Bolivariana.

A principal crítica que se faz ao Estado é sua falta global de eficácia e produtividade no âmbito das novas exigências impostas pela globalização: ele custa caro demais em comparação com as vantagens que oferece à coletividade e põe entraves à competitividade da economia. É, portanto, a uma análise econômica que se deseja submeter a ação pública para discriminar não apenas as agendas e as não agendas, mas a própria maneira de realizar agendas (DARDOT; LAVAL, 2016, p.273).

Em documento confidencial despachado no dia 15 de junho de 2004, intitulado Chávez v Chávez: What's his plan?, é feita uma leitura sobre as Missões chavistas, considerando-as programas populistas, ${ }^{54}$ considerando tais investimentos na promoção social como estratégia de compra de voto:

In his rhetoric, Chavez is putting his populist programs such as Mission Robinson (literacy) and Mission Sucre (college scholarships) on the line. His message to voters is that the opposition will take away these programs if they return to power. To a considerable degree these missions have been thinly disguised transfer payments to his key low-income constituents. [...] Chavez also has to deal with the curious fact that some 233,000 recipients of Mission benefits also signed the petition against him, suggesting that some votes, at least, are not for sale ${ }^{55}$

O documento, por considerar os programas sociais chavistas como populista, os relaciona com compra de votos por parte do governo, que busca conquistar votos com base no oferecimento pelo Estado de programas de saúde e educação. Ao relacionar a preferência do

\footnotetext{
${ }^{54}$ Outro documento que critica as Missões pode ser encontrado em: Doc. Confidential n ${ }^{\circ} 12997$. Inside Barrio Adentro: The BRV's primary Health Care program. 21/08/2006. Disponível em: https://wikileaks.org/plusd/cables/06CARACAS2489 a.html e em: Doc. Confidential no 10442 . VIEWS ON BARRIO ADENTRO FROM CUBAN DOCTORS. 05/12/2006. Disponível em: https://wikileaks.org/plusd/cables/06CARACAS3548 a.html

55 "Em sua retórica, Chávez está colocando em risco seus programas populistas, como Mission Robinson (alfabetização) e Mission Sucre (bolsas universitárias). Sua mensagem para os eleitores é de que a oposição tirará esses programas se eles retornarem ao poder. Em um grau considerável, essas missões têm sido pagamentos de transferências disfarçados para seus principais integrantes de baixa renda. [...] Chávez também tem que lidar com o curioso fato de que cerca de 233 mil beneficiários de benefícios da Missão também assinaram a petição contra ele, sugerindo que alguns votos, pelo menos, não estão à venda."

56 Doc. Confidential no13179. Chavez v Chavez: What's his plan? 25/06/2004. Disponível em: https://wikileaks.org/plusd/cables/04CARACAS2081_a.html
} 
eleitorado que tem acesso aos programas sociais a Chávez, a diplomacia estadunidense não menciona que esta parcela da população estava tendo contato com médicos e oportunidades de educação pela primeira vez, fato que representa uma mudança considerável na qualidade de vida dessas pessoas, ou seja, ao considerar o voto em Chávez à compra de voto, o documento não leva em consideração as condições materiais envolvidas nas questões.

\section{Considerações Finais}

O artigo buscou analisar, através de documentos disponíveis no site Wikileaks, como os EUA buscaram organizar setores da sociedade civil venezuelana com o objetivo de desestabilizar e interromper o governo de Hugo Chávez. Tal estratégia se deu em função da mudança na correlação de forças políticas, sociais e econômicas que a chegada de Chávez à presidência representou em 1998, em particular pela tentativa de alterar a relação entre o Estado e a sociedade no país, buscando uma maior participação estatal nos ganhos provenientes do petróleo e, dessa forma, utilizando do aumento da arrecadação para colocar em prática uma série de políticas públicas que visavam distribuir renda e oferecer serviços de necessidade básica para os venezuelanos.

A maior participação do Estado na extração do petróleo foi entendida como uma ameaça aos negócios dos EUA no país e na América Latina, uma vez que o país depende, em grande medida, do petróleo venezuelano e conta com capitais investidos na extração do óleo venezuelano. Assim sendo, os EUA utilizaram sua embaixada em Caracas para organizar e financiar a oposição ao governo democraticamente de Hugo Chávez, principalmente após o fracasso do golpe militar de 2002.

No processo de organização e financiamento da oposição, as ONGs ganharam um papel fundamental, uma vez que foi por meio delas que diferentes fundações e instituições estadunidenses conseguiam influência entre os atores oposicionistas através de financiamento e orientações programáticas sobre processos eleitorais e na elaboração de políticas públicas que se contrapunham às propostas pelo governo de chavista.

Além da questão econômica, ou seja, o interesse direto dos EUA no petróleo venezuelano, também existe uma questão ideológica e hegemônica na atuação do Estado venezuelano durante o governo Chávez. Desde os anos de 1980, os países da América Latina foram compelidos a adotarem uma agenda fortemente neoliberal, o que pressupõem o 
esvaziamento das funções do Estado no que diz respeito ao oferecimento de serviços básicos para a população e de regulamentação financeira e produtiva, construindo uma base social onde as práticas de sociabilidade comunitárias são substituídas pela concorrência e pela meritocracia (PAULANI, 2008, p.68).

O neoliberalismo é a razão do capitalismo contemporâneo, de um capitalismo desimpedido de suas referências arcaizantes e plenamente assumido como construção histórica e norma geral da vida. O neoliberalismo pode ser definido como o conjunto de discursos, práticas e dispositivos que determinam um novo modo de governo dos homens segundo o princípio universal da concorrência (DARDOT; LAVAL, 2016, p.17).

Dessa forma, mesmo com suas limitações e contradições, inerentes a qualquer processo de transformação social, o chavismo e a Revolução Bolivariana ao defender uma maior participação do Estado na extração do petróleo, na construção de um sistema de segurança social, de maior participação democrática e de organização social se afastava dos pressupostos defendidos pelo neoliberalismo, o que explica a oposição dos EUA aos programas sociais chavistas.

Por fim, a documentação demonstra como os EUA buscaram atuar na base chavista através de ONGs, que em consonância com o discurso opositor e neoliberal para desarticular o governo eleito na Venezuela com a intenção de impor seus interesses econômicos no país, ou seja, controlar as maiores reservas de petróleo do mundo, e acabar com uma experiência social que, se não buscava romper com a ordem capitalista, se afastava do ideário neoliberal através de incentivos e práticas de caráter comunitárias e autogestão.

\section{Bibliografia}

CICCARIELLO-MAHER, George. Building the commune: Radical democracy in Venezuela. Verso Books, 2016.

CICCARIELLO-MAHER, George. We created Chávez: A people's history of the Venezuelan revolution. duke university press, 2013.

CORONIL, Fernando. El Estado mágico: naturaleza, dinero y modernidad en Venezuela. Editorial Alfa, 2017.

DARDOT, Pierre; LAVAL, Christian. A nova razão do mundo. Boitempo Editorial, 2016. 
PAULANI, Leda. Brasil delivery: servidão financeira e estado de emergência econômico. Boitempo Editorial, 2008.

SALGADO, Tiago Santos. A Folha de S. Paulo e o Governo Hugo Chávez (2002 - 2005). Jundiaí, Paco Editorial: 2015

SCHOULTZ, Lars. Estados Unidos: poder e submissão uma história da política norteamericana em relação à América Latina. Edusc, 2000.

SEABRA, Raphael. "A revolução venezuelana: chavismo e bolivarianismo" in Sociedade e Cultura 13.2 (2010).

\section{Documentação:}

Doc. Confidential. n9521. Das Deshazo's meeting with g-5 apposition leaders 21/01/2004. Disponível em: https://wikileaks.org/plusd/cables/04CARACAS295_a.html

Doc. Unclassified. n9443. Human rights strategy for Venezuela. 04/02/2004. Disponível em: https://wikileaks.org/plusd/cables/04CARACAS425_a.html

Doc. Unclassified. n³1401. Update on the USAID/OTI Venezuela program. 11/02/2004. Disponível em: https://wikileaks.org/plusd/cables/04CARACAS501_a.html

Doc. Confidential - $\mathrm{n}^{\mathrm{0}} 10035$. The "Tropical Unity" of the opposition. 12/02/2004. Disponível em: https://wikileaks.org/plusd/cables/04CARACAS533_a.html

Doc. Confidential n'5131. Chavez Takes aim at human rights organization. 20/02/2004.

Disponível em: https://wikileaks.org/plusd/cables/04CARACAS612_a.html.

Doc. Confidential, n4563. Chavez accuses usg of funding "coupmongers". 26/02/2004. Disponível: https://wikileaks.org/plusd/cables/04CARACAS634_a.html/

Doc. Confidential $\mathrm{n}^{\circ}$ 5972. Request for additional funds to help strengthen local governments and civil society groups. 27/03/2009. Disponível em: https://wikileaks.org/plusd/cables/09CARACAS404_a.html

Doc. Confidential $n^{\circ} 9027$. Venezuela: Potential fraud in the appeals process 05/05/2004. Disponível em: https://wikileaks.org/plusd/cables/04CARACAS1507_a.html

Doc. Confidential. $\mathrm{n}^{\circ} 7588$. Chavez: Coup attempt averted with arrest of "paramilitaries. 11/05/2004. Disponível em: https://wikileaks.org/plusd/cables/04CARACAS1543_a.html

Doc.Confidential. $\mathrm{n}^{\circ}$ 4987. Ambassador meets with Sumate leaders 16/06/2004. Disponível em: https://wikileaks.org/plusd/cables/04CARACAS1993_a.html 
Doc. confidential nº682. No Progress on poverty under Chávez. 17/06/2004. Disponível em: https://wikileaks.org/plusd/cables/04CARACAS2003_a.html

Doc. Confidential $\mathrm{n}^{\circ} 13179$. Chavez v Chavez: What's his plan? 25/06/2004. Disponível em: https://wikileaks.org/plusd/cables/04CARACAS2081_a.html

Doc. Confidential. no 10445. Opposition launches "National consensus plan. 5/07/2004. Disponível em: https://wikileaks.org/plusd/cables/04CARACAS2248_a.html

Doc. Confidential. n4576. Citizens assemblies: civil society gets organized. 28/07/2004. Disponível em: https://wikileaks.org/plusd/cables/04CARACAS2389_a.html

Doc. Confidential. N6352. Visit to mass market and Bolivarian school. 10/12/2004. Disponível em: https://wikileaks.org/plusd/cables/04CARACAS3817_a.html

Doc. Confidential. $n^{\circ} 12763$. Chavez gives marching orders for the Revolution. 23/12/2004. Disponível em: https://wikileaks.org/plusd/cables/04CARACAS3928_a.html

Doc. Confidential n'10442. VIEWS ON BARRIO ADENTRO FROM CUBAN DOCTORS. 05/12/2006. Disponível em: https://wikileaks.org/plusd/cables/06CARACAS3548_a.html

Doc.Confidential. n'9345. USAID/OTI WATCHDOGS START TO SHED LIGHT. 26/01/2007. Disponível em: https://wikileaks.org/plusd/cables/07CARACAS175_a.html

Doc. Confidential. $n^{\circ}$ 8999. NGOS CITE WORRISOME HUMAN RIGHTS PATTERNS. 04/10/2007. Disponível em: https://wikileaks.org/plusd/cables/07CARACAS1969_a.html.

SUllivan. Mark. Venezuela: Political Conditions and U.S Policy. 2008. Congressional Research Service. Disponível em: https://file.wikileaks.org/file/crs/RL32488.pdf

Doc. Confidential nº16351. Venezuelas's 2009 economic outlook: Grim to Dire. 22/01/2009. Disponível em: https://wikileaks.org/plusd/cables/09CARACAS87_a.html

\section{A Ação dos EUA na Venezuela: ONGs, Sociedade Civil e Neoliberalismo}

\footnotetext{
Resumo

O presente artigo tem como objetivo demonstrar como se deu a ingerência dos EUA na Venezuela durante o governo de Hugo Chávez através da análise da documentação disponibilizada no site Wikileaks que tornou público o acesso a documentos secretos produzidos pelo Congresso dos EUA e pela embaixada estadunidense em Caracas. Tal análise permite perceber como o governo dos EUA atuou como organizador e financiador da oposição venezuelana ao governo democraticamente eleito de Chávez, em particular através da atuação de ONGs, que atuavam para defender os interesses dos EUA no país e como difusoras do discurso neoliberal dentro das bases chavistas.

Palavras-chave: Hugo Chávez; EUA; Neoliberalismo; Wikileaks
} 


\title{
US Action in Venezuela: NGOs, Civil Society and Neoliberalism
}

\begin{abstract}
This article aims to demonstrate how the US intervened in Venezuela during the government of Hugo Chavez through the analysis of the documentation made available on the Wikileaks website that made public access to secret documents produced by the US Congress and the US Embassy in Caracas. This analysis shows how the US government acted as the organizer and financier of the Venezuelan opposition to the democratically elected government of Chávez, in particular through the activities of NGOs that worked to defend US interests in the country and as diffusers of neoliberal discourse within chavista bases.
\end{abstract}

Keywords: Hugo Chávez; USA; Neoliberalism; Wikileaks

\section{La Acción de EEUU en Venezuela: ONGs, Sociedad Civil y Neoliberalismo}

\section{Resumen}

El presente artículo tiene como objetivo demostrar cómo se dio la injerencia de EEUU en Venezuela durante el gobierno de Hugo Chávez a través del análisis de la documentación disponible en el sitio Wikileaks que hizo público el acceso a documentos secretos producidos por el Congreso de Estados Unidos y la embajada estadounidense en Caracas. Este análisis permite percibir cómo el gobierno de Estados Unidos actuó como organizador y financiador de la oposición venezolana al gobierno democráticamente electo de Chávez, en particular a través de la actuación de ONGs, que actuaban para defender los intereses de EEUU en el país y como difusoras del discurso neoliberal dentro de las elecciones, bases chavistas.

Palabras clave: Hugo Chávez; EE.UU.; neoliberalismo; Wikileaks 